\title{
Tenofovir-associated kidney disease in Africans: a systematic review
}

\author{
Takudzwa J. Mtisi ${ }^{* *} \mathbb{D}$, Chiratidzo E. Ndhlovu², Chiedza C. Maponga ${ }^{3}$ and Gene D. Morse ${ }^{4}$
}

\begin{abstract}
Background: Data on chronic kidney disease development in HIV infection is important towards building a comprehensive knowledge of HIV, ageing and polypharmacy in Africa. Several previous studies on tenofovir-associated kidney disease in Africa have shown conflicting results. This review summarises what is known about the development of kidney disease in HIV-positive African patients on tenofovir disoproxil fumarate (TDF)-containing ART. We set out to document the occurrence of kidney disease in HIV-positive Africans on TDF-containing ART in population-based studies and to evaluate the renal safety of TDF in Africans.

Methods: We conducted a systemic review using published studies which were identified through a computerized search of original research using the Medline/PubMed database, EMBASE, EBM Reviews, Proquest Google Scholar and Global Health reported from inception until 5 October 2017. Two reviewers independently abstracted the data and performed quality assessment of the included studies. We screened 595 articles and included 31 in the qualitative analysis performed.

Results: A total of 106406 patients (of whom 66,681 were on Tenofovir) were involved in these 31 studies with sample sizes ranging from 30 to 62,230 . Duration on tenofovir-containing ART ranged from those initiating ART at baseline to those who received TDF for up to 9 years. All but one of the studies involved only patients 16 years and older. The studies had differing definitions of kidney dysfunction and were of variable study design quality. The documented outcomes had substantial discrepancies across the studies, most likely due to methodological differences, study size and disparate outcome definitions.
\end{abstract}

Conclusions: Our review identified studies in Africans reporting statistically significant renal function decline associated with TDF use but the clinical significance of this effect was not enough to contraindicate its continued use in ART regimens. Consistent with studies in other populations, patients are at greater risk if they have pre-existing renal disease and are more advanced in age. More research is needed on paediatric populations under 16 years of age. Trial registration This review was registered on Prospero (registration number CRD42018078717).

Keywords: Tenofovir, Renal, Africans

\section{Background}

Tenofovir disoproxil fumarate (TDF or commonly termed "tenofovir") is a Nucleoside Reverse Transcriptase Inhibitor (NRTI) that acts by blocking reverse transcriptase, an enzyme critical for viral production in HIV-infected people. It is still widely used as part of first-line antiretroviral

\footnotetext{
*Correspondence: takudzwamtisi@gmail.com

${ }^{1}$ Department of Clinical Pharmacology, University of Zimbabwe College of Health Sciences, Harare, Zimbabwe

Full list of author information is available at the end of the article
}

therapy (ART) in resource limited settings such as in Africa. It is administered orally and is widely distributed with the highest concentrations occurring in the kidney and liver $[1,2]$. The major route of elimination is through the kidneys via glomerular filtration and tubular secretion and its clearance is in the proximal tubule of the nephron is controlled by active transport [1]. Higher tenofovir plasma levels result in intracellular accumulation in the renal tubular cells a consequent increased risk of renal toxicity [1]. Genetic variation in these transporters may also influence exposure of the kidney to tenofovir,

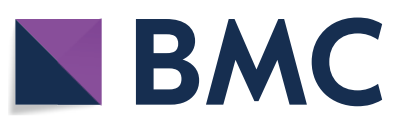

(c) The Author(s) 2019. This article is distributed under the terms of the Creative Commons Attribution 4.0 International License (http://creativecommons.org/licenses/by/4.0/), which permits unrestricted use, distribution, and reproduction in any medium, provided you give appropriate credit to the original author(s) and the source, provide a link to the Creative Commons license, and indicate if changes were made. The Creative Commons Public Domain Dedication waiver (http://creativecommons.org/ publicdomain/zero/1.0/) applies to the data made available in this article, unless otherwise stated. 
hence play a role in tenofovir associated renal toxicity [2-7].

While TDF has been shown to be effective and relatively safe, several studies indicate that it has nephrotoxic potential, characterised by proximal tubular cell injury which may result in acute kidney injury (AKI), chronic kidney disease (CKD) or partial or complete Fanconi syndrome [5, 8-11]. This may compound HIV associated nephropathy (HIVAN), a condition which is a leading cause of chronic kidney disease and end-stage renal disease (ESRD) and is caused by direct injury to the kidneys by the Human Immunodeficiency Virus (HIV) [12]. HIVAN is documented as being more common in African Americans that their white counterparts but has wide variability in different Sub-Saharan populations [13, 14]. AKI usually results in discontinuation of the drug while chronic manifestations may be managed by closer monitoring of the patient and treating symptomatically. Regardless of the underlying aetiology of kidney disease, if left untreated, it may lead to death [15]. Initiating patients with reduced estimated glomerular filtration rates (eGFR) of $<50 \mathrm{ml} / \mathrm{min} / 1.73 \mathrm{~m}^{2}$ on TDF containing ART has been shown to increase the risk for renal dysfunction in the said patients [15]. In developed countries, although ART continues to be given to patients with renal disease, if indicated, most NRTIs must be dosed according to renal function and some ARVs are avoided $[14,16]$.

Several studies conducted in Africa provide conflicting evidence on the renal outcomes of HIV-positive African patients on TDF. This necessitated a review that provides a resource to summarise specific data required for objective decision making on the renal safety of TDF in African populations.

\section{Rationale}

The advent of anti-retroviral therapy has resulted in patients living longer with HIV. However, this is not without consequence. As these patients age, they are at increased risk of developing chronic conditions such as hyperlipidemia, cardiovascular disease (CVD) and chronic kidney disease (CKD). The consequent polypharmacy in trying to manage the multiple conditions in the patient, which includes use of medicines like TDF reported to cause renal disease may also further compound the burden on the HIV positive patient. Debate continues over whether widespread use of TDF, particularly in "real world" clinical settings, poses a risk for nephrotoxicity significant enough to limit its use, to necessitate close clinical monitoring or to identify high risk patients at initiation and closely monitor them $[11,17,18]$. In recent years, the option of tenofovir alafenamide (TAF) has arisen as it is documented to have a safer renal profile than TDF. TAF has a similar tolerability, safety, and effectiveness to TDF and probably less adverse events related to renal and bone density outcomes in the treatment of naive and experienced patients with HIV-1 [19]. Given that TAF is documented as having higher viral suppression rates and better renal safety and bone density safety profiles, it has better clinical advantages over TDF and could be considered to replace TDF. Knowing the extent of renal safety of TDF in low resource settings (LRSs) would inform policy as to the need or priority to change patients to TAF.

The data on co-morbidity in HIV infection is especially important when considering HIV in Africa coupled with ageing and polypharmacy and the implications in such resource limited settings. We reviewed the existing literature on acute kidney injury and TDF-associated nephrotoxicity not to provide a systematic literature review with weighted evidence, but rather to provide a collated source of evidence from available sources. We aimed to summarise what is known about the development of kidney disease in HIV positive African patients on TDF containing ART, from verified data sources. The specific objectives were:

- To document the occurrence and patterns thereof, of kidney disease in HIV-positive Africans on TDFcontaining ART in population-based studies.

- To evaluate the renal safety of TDF in African HIV positive patients.

\section{Methods}

\section{Study design}

A systematic review was conducted according to the Preferred Reporting Items for Systematic Reviews and MetaAnalyses (PRISMA) group [20].

\section{Eligibility criteria, data sources and study selection}

We performed a systematic search of English articles from the following electronic databases from inception to the date of search as indicated: Pubmed (5 October 2017), Embase (5 October 2017), EBM reviews (5 October 2017). We also considered grey literature in the form of reports of original studies, unpublished master's thesis and PhD dissertations written in English in ProQuest Dissertations and Thesis Global database. Meeting abstracts archives of International AIDS Conference (IAS), International Conference on AIDS and Sexually Transmitted Infections in Africa (ICASA), African Society for Laboratory Medicine (ASLM) were also searched for any relevant unpublished work as long as they 
reported renal outcomes of African HIV patients on TDF. We included data from primary research of cross-sectional studies, observational cohort, case-control studies and randomized control trials reporting renal outcomes of HIV positive patients on a TDF-containing regimen. Studies done on Africans residing on the continent satisfying the PICOS criteria in Table 1 were included. Articles that were not written in English, commentary, editorials, reviews, publications in duplicate and articles only available in abstract form were not included in the review. Selection of articles was done in three phases: titles alone, abstracts, and then full text articles.

\section{Search}

The following search terms were used: ("Kidney dysfunction" OR "Kidney impairment" OR "Kidney failure" OR "Renal disease" OR "Renal dysfunction" OR "Renal impairment" OR "Renal failure") AND ("HIV seropositive") AND (TDF OR "Tenofovir Disoproxil Fumarate") AND ("Antiretroviral therapy" OR "ART" OR "Highly Active Antiretroviral therapy") AND (Africa OR Africans OR Blacks OR "Black Africans"). The terms were adjusted as appropriate for searching in each respective database (Additional file 1).

\section{Data abstraction}

Two reviewers (TM and $\mathrm{AH}$ ) independently reviewed all titles and abstracts of the search results in two phases. The retrieved titles and abstracts were reviewed first to

\section{Table 1 Inclusion criteria}

\begin{tabular}{ll}
\hline Study design & Cohort \\
& Case-control \\
& Cross-sectional (if duration of TDF therapy is \\
stated) & RCT \\
Full articles & Open access dissertations/theses \\
Article characteristics & Grey literature \\
& Africans \\
Pll age groups & HIV positive on TDF containing ART \\
Primary research done on the African continent & TDF containing ART \\
Sidney dysfunction. Indicated by any of the \\
following outcome measurements: \\
Glycosuria, phosphaturia \\
Outcome \\
CrCl and eGFR data \\
Serum creatinine data \\
Albumin creatinine ratio \\
Protein creatinine ratio \\
\hline
\end{tabular}

identify relevant studies against the inclusion criteria in Table 1.

The study eligibility criteria checklist was piloted on ten publications to check for consensus interpretation and classification of studies. Full texts of selected studies were then retrieved and read to determine eligibility for inclusion in the qualitative analysis. A PRISMA study flow diagram of included and excluded studies was developed showing reasons for exclusion (Fig. 2).

A data extraction form designed to focus on population, study design, methodology and outcome was developed. One reviewer used this to extract the data from all the studies identified at screening (TM). A second reviewer $(\mathrm{AH})$ checked for errors. Three discrepancies were noted, discussed, resolved by consensus and amended as required. Microsoft Excel was used for the management of data.

\section{Risk of bias assessment}

We used the NIH Quality Assessment Tool for Cohort and Cross Sectional Studies (National Institutes of Health, 2014) checklist. Each of the 16 items on the checklist was assigned a score of 1 (yes) or 0 (no or CD, cannot determine; NA, not applicable; NR, not reported). Scores were then collated across items to give an overall quality score ranging from 0 to 16 . Each of the studies was then rated as being of low, moderate, or high methodological quality depending on the number of questions answered as "yes (low risk of bias)". Studies were deemed high quality if they had scores higher than 13 , moderate if they had a score of 8-12, and low a score of 7 or lower.

\section{Ethics statement}

Since this research was a systemic review based on the data extraction of published articles, ethical approval was not necessary and was therefore, not sought.

\section{Results}

Identified studies (Fig. 1)

We retrieved a total of 595 articles from six databases namely Pubmed Central, EMBASE, EBM Reviews, Global Health, Proquest and Google Scholar. Ninetyfour duplicates were removed after merging the articles. Of the remaining 501 articles, 378 were removed on the basis of ineligibility of their titles and/or abstracts to satisfy the inclusion criteria as defined in Table 1. One abstract fit the inclusion criteria but no manuscript was available for analysis and hence the abstract was excluded [21]. Full text articles were then retrieved for 123 articles of which 92 were excluded for reasons specified in Fig. 1 leaving 31 suitable articles for this review that included a total of 106406 participants. 


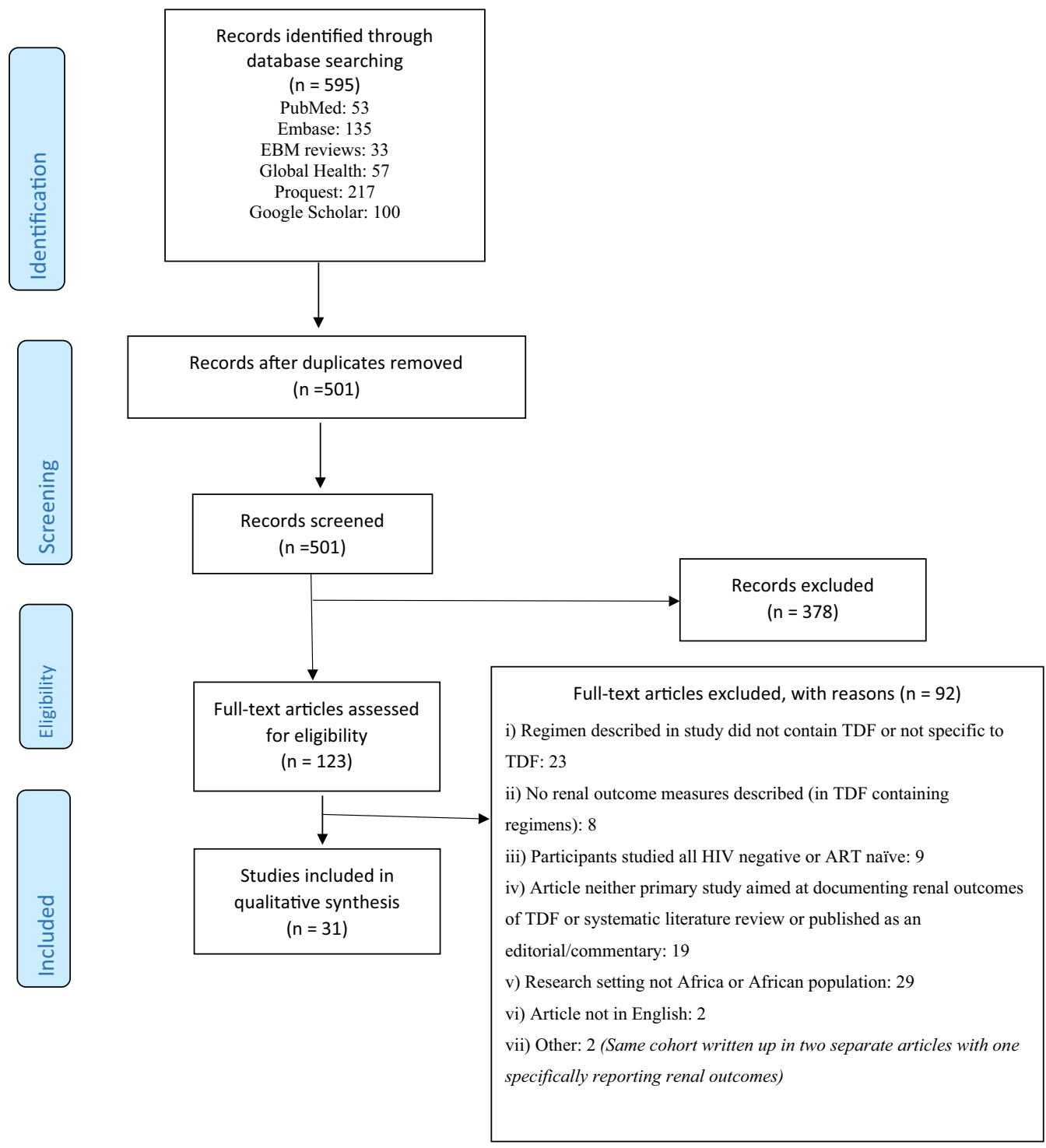

Fig. 1 Literature search results

\section{Characteristics of included studies (Table 2)}

Of the 31 studies included in this analysis, 18 were cohort studies, 11 of which were retrospective cohorts $[15,22-$ 39]. Seven studies were cross-sectional [40-46], two randomized control trial (RCT) [47, 48], two observational analyses within RCTs $[49,50]$, one prospective case control study [51] and one was in the form of targeted spontaneous reporting within the context of implementation research [52]. Sample sizes ranged from 30 to 62 230. The duration on tenofovir-containing ART ranged from 0 to 9 years.

While TDF was included in the ART regimens in all the studies, there was wide variation in ART combinations and concurrent medications and durations thereof. Not all studies reported concurrent medications. Ten studies $[15,23,24,29,32,35,39,47,49$, 50] recruited only participants who were TDF naïve at baseline while the rest recruited patients who were TDF experienced for at least 6 months. The median age of the participants across all the studies ranged from 34 to 43 years with all studies including more females than males. All studies except one included only adult patients with the one that included patients aged $\geq 13$ years being pregnant females. Less than $50 \%$ of the studies reported CD4 counts at the baseline, at study end or both. Of those that did, baseline CD4 counts were low $(<200)$ at baseline and for those that reported at study end, these had improved. 


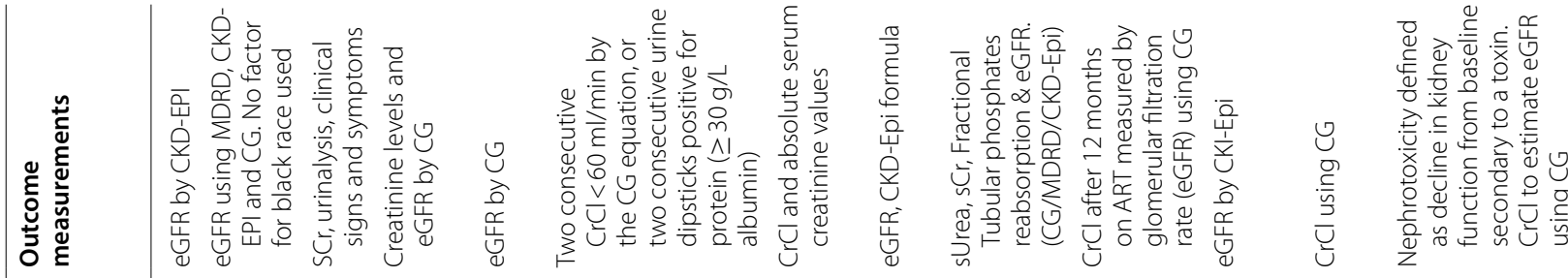

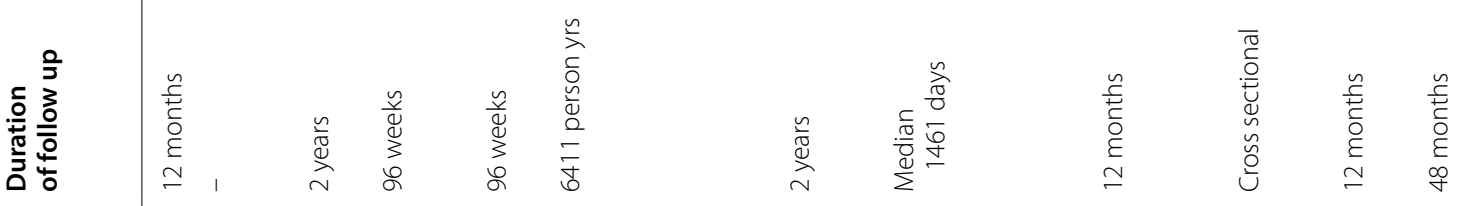
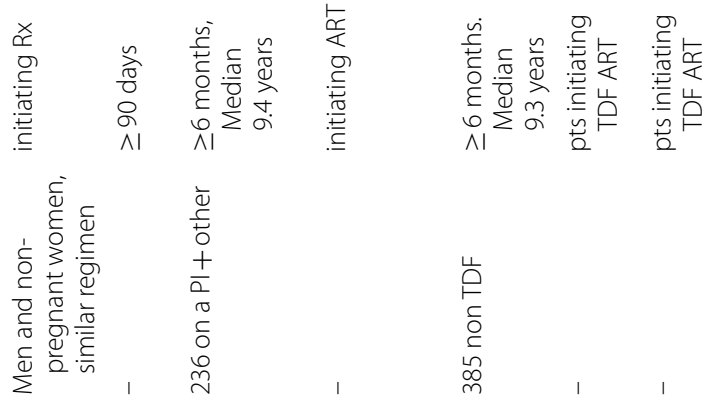

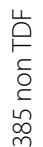

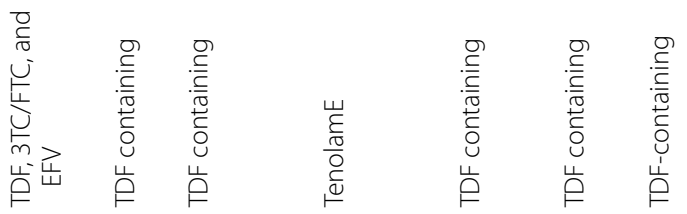

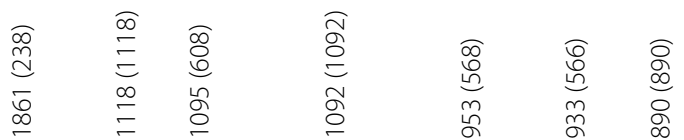

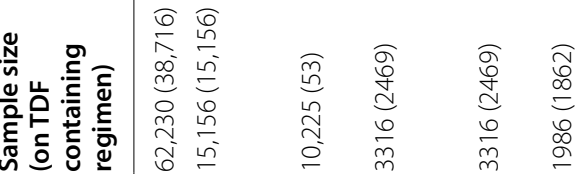

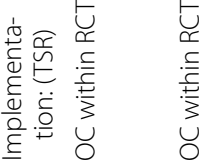

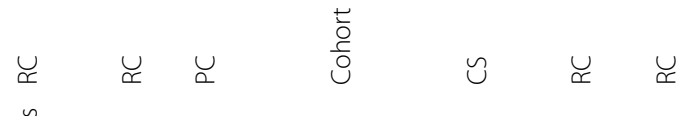

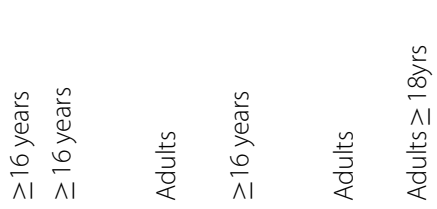

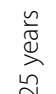

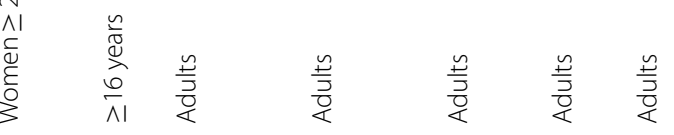

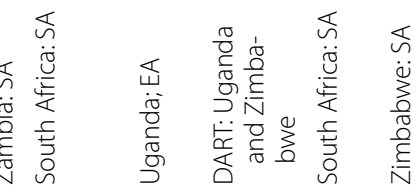

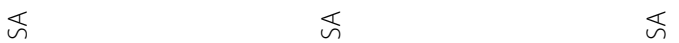

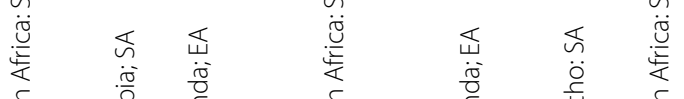

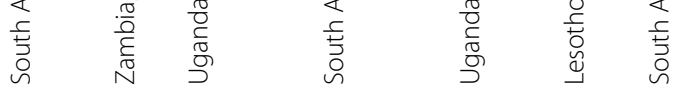

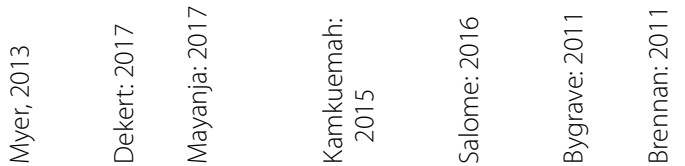




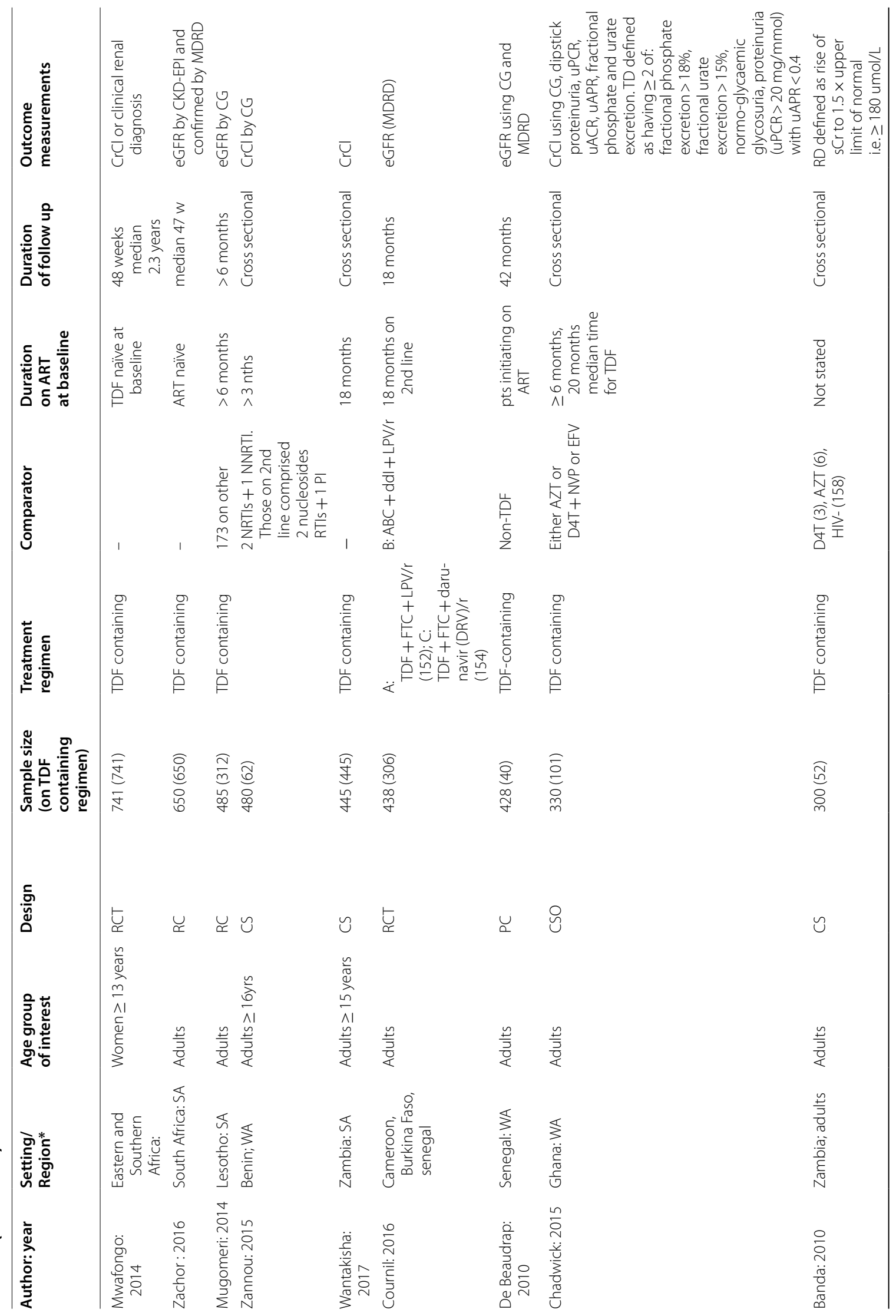




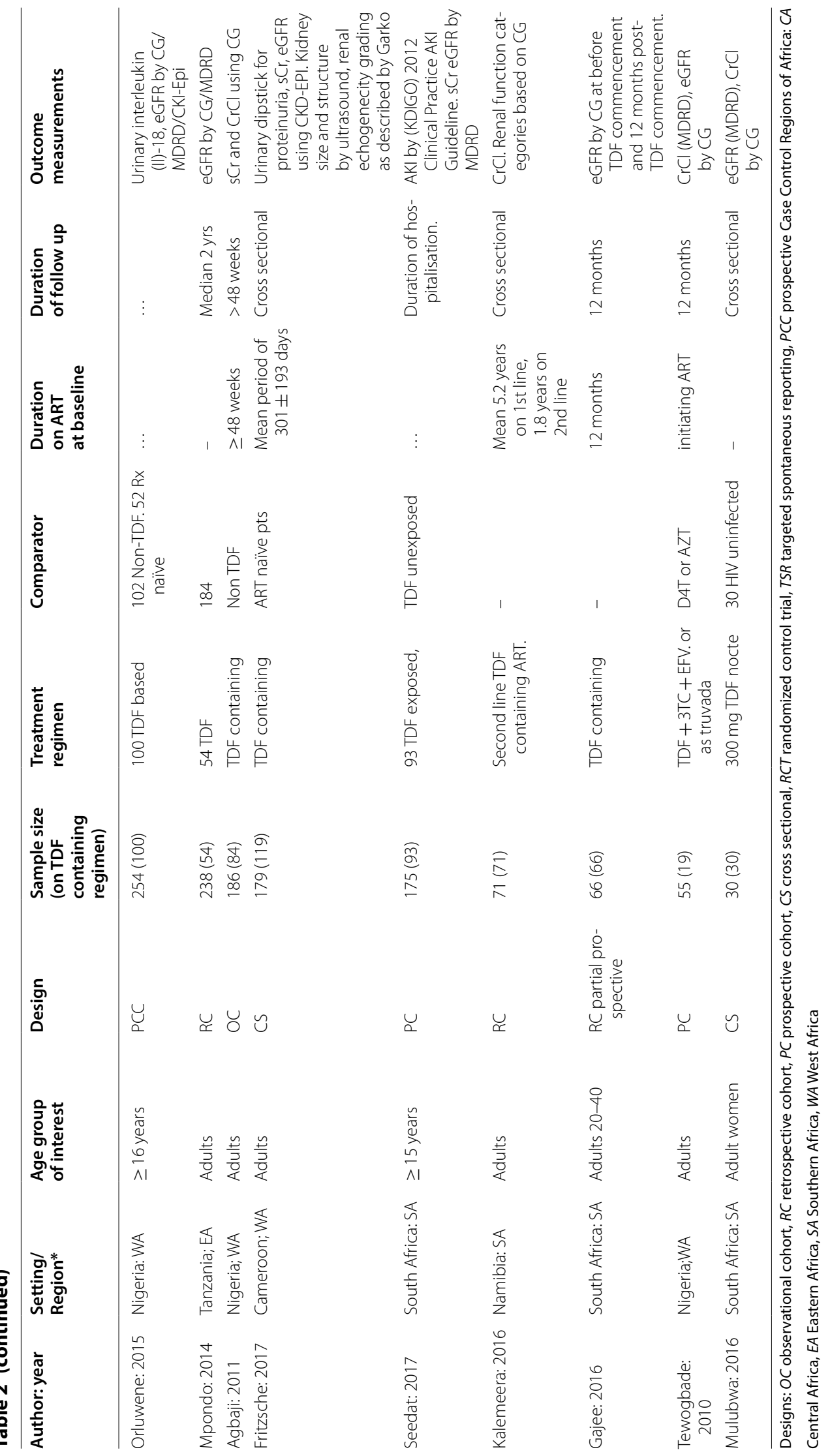




\section{Renal parameters reported}

Table 2 illustrates that renal outcomes were variably defined across the studies. In about $60 \%$ of the included studies, eGFR (using one of or a combination of CockCroft-Gault, MDRD, CKI-EPI formulae) was used as a measure of renal outcomes. Another 33\% reported at least Creatinine clearance $(\mathrm{CrCl})$ as the outcome measurement [22, 25, 28, 30-32, 49-51]. Only two studies by Zachor et al. and Banda et al. [40, 52] reported only serum creatinine $(\mathrm{sCr})$ with Zachor defining renal dysfunction as the rise of $\mathrm{sCr}$ to 1.5 times the upper limit of normal, i.e. $\geq 180 \mathrm{umol} / \mathrm{L}$ and Banda reporting $\mathrm{sCr}$, urinalysis, clinical signs and symptoms as measures of renal dysfunction. In addition to reporting $\mathrm{CrCl}$, Myer et al. also reported absolute serum creatinine values [36].

\section{Renal safety outcomes}

Table 3 summarises the findings and conclusions made by the various authors from their studies. About $90 \%$ of the studies focused on chronic outcomes of kidney function in patients on TDF-containing ART while two reported on acute outcomes [34, 35, 51]. Most of the studies reported at least some incidence of $\mathrm{RD}$ in the patients taking TDF containing ART. Fifteen report overall safety of TDF in ART regimens, recommending its continued use with monitoring [28-31, 37-40, 42, 44, 46, 48-50]. Although the definitions of renal dysfunction differed widely, the other 16 studies report either statistical or clinical association of TDF with renal dysfunction [15, 22-26, 32-35, 43, 45, 47, 51-53]. Groups at higher risk include patients with impaired renal function at baseline, older age groups and women [33, 35, 47]. Mulenga et al. and Mwafongo et al. suggest that development of renal dysfunction is more likely during the first year of using TDF. Zachor et al. report that the risk of developing stage 3 CKD increases by up to 1.9 -fold for every 10 year increase in age and women are four times more likely to develop end stage CKD than their male counterparts. Further, three studies focused on pregnant women; all reporting different outcomes from each other.

\section{Discussion}

Our review is the first to systematically document renal outcomes of patients on tenofovir-containing ART in African populations. We identified 31 eligible studies involving a total of 106, 406 participants in 14 countries. These included five countries of Southern Africa, five from West Africa, three from East Africa and one from Central Africa (Fig. 2).

The results (summarised in Table 3 ) indicate conflicting evidence of the association of TDF with renal dysfunction. During follow up terms of up to 9 years, $50 \%$ of the studies suggest overall safety of tenofovir while the other half report varying levels of renal toxicity due to TDF. Fifteen studies reported that there is neither statistical nor clinical association of TDF with renal function decline in HIV-positive patients [27-31, 36-40, 42, 44, 46, 48-50]. Although some recommend monitoring of patients particularly those with deranged renal function parameters at baseline, there is, no consensus on recommended monitoring strategies to this end. On the other hand, 16 studies reported an association with seven of these reporting the association as significant (Table 3) [15, 22-26, 32-35, 43, 45, 47, 5153]. Five of the seven were done in Southern Africa [25, $34,35,43,45]$. One study could not make an assessment of whether or not TDF was associated with renal function decline in these patients [47]. Unfortunately, of the studies included in this review, only four systematically documented other non-ART co-medications that these patients were taking thereby making it difficult to make assessments of the impact of other drugs on the results or to conclusively attribute the impact on renal function of TDF containing ART of the studies in this review [25, 26, 28, 47]. However, Cournil et al. suggest that an interaction between Tenofovir and Ritonavir may be responsible for an initial decrease in eGFR observed when a patients initiates on a ritonavir boosted TDF regimen. In a recent review by Hill et al. the authors support this finding that TDF toxicity occurs when it is used with boosting agents such at ritonavir [54]. This is important in cases where Protease inhibitor (PI) boosted regimens are required in second and third line therapy. In ageing HIV populations with increased lifespans, second and third line therapy is particularly important and close monitoring of these patients cannot be over-emphasized.

The mean duration on TDF treatment of the studies was less than 3 years in most studies with two studies both from Uganda reporting outcomes in patients who had taken the drug for a median of 9 years as a drug that can be safely given without serious renal implications [30, 44]. The Zambian study reported by Watankisha found a high burden of renal dysfunction in older patients with low CD4 counts reporting point prevalence of kidney dysfunction among these patients as $18.6 \%$ at 18 months follow up [45].

There was no consistency in the outcome being measured (Table 1). More importantly, while it is understood that TDF specifically affects proximal tubular dysfunction, the studies in this review generally did not systematically use tests specific for proximal tubular dysfunction such as Fanconi syndrome $[41,55,56]$. 


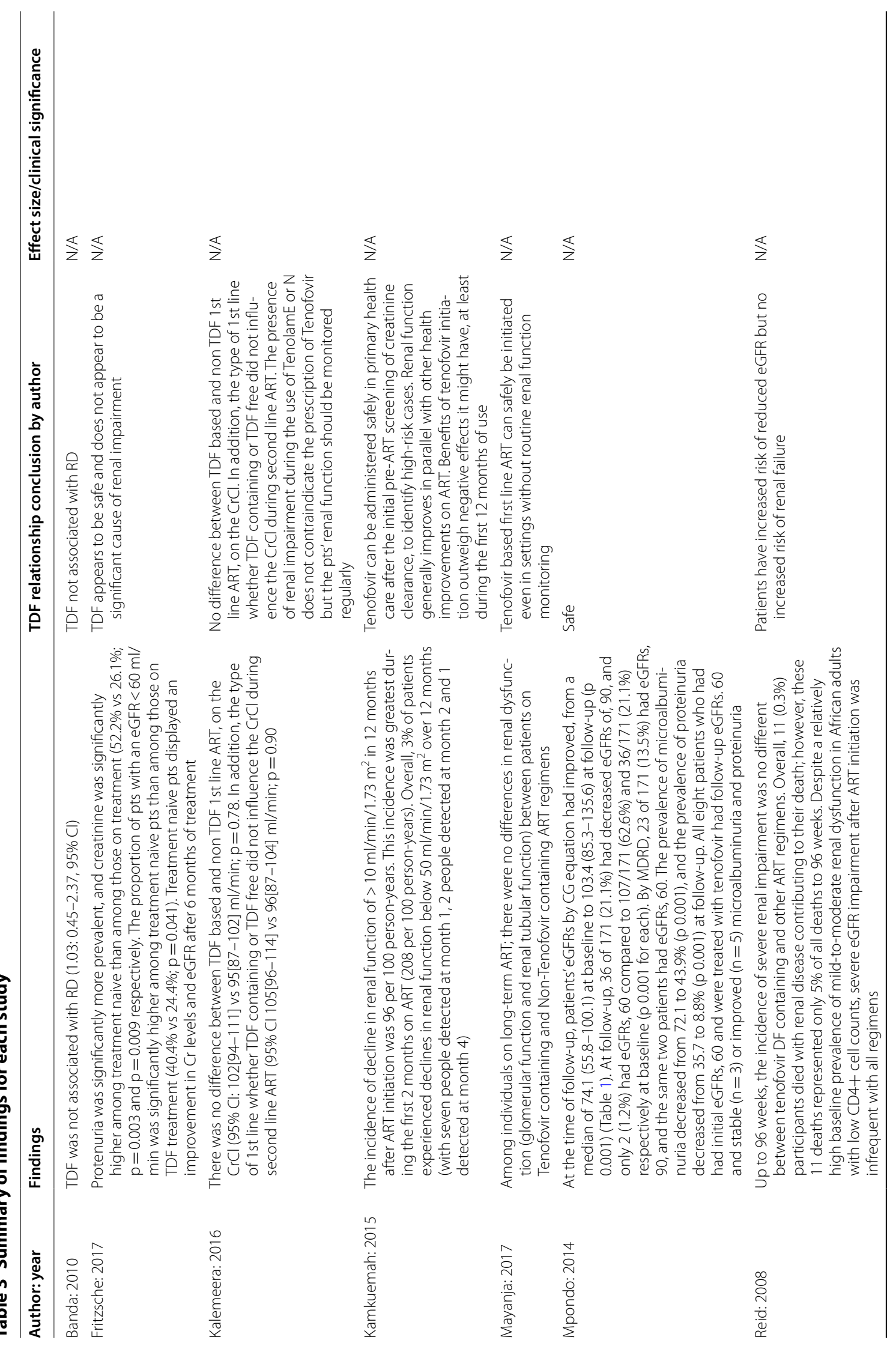




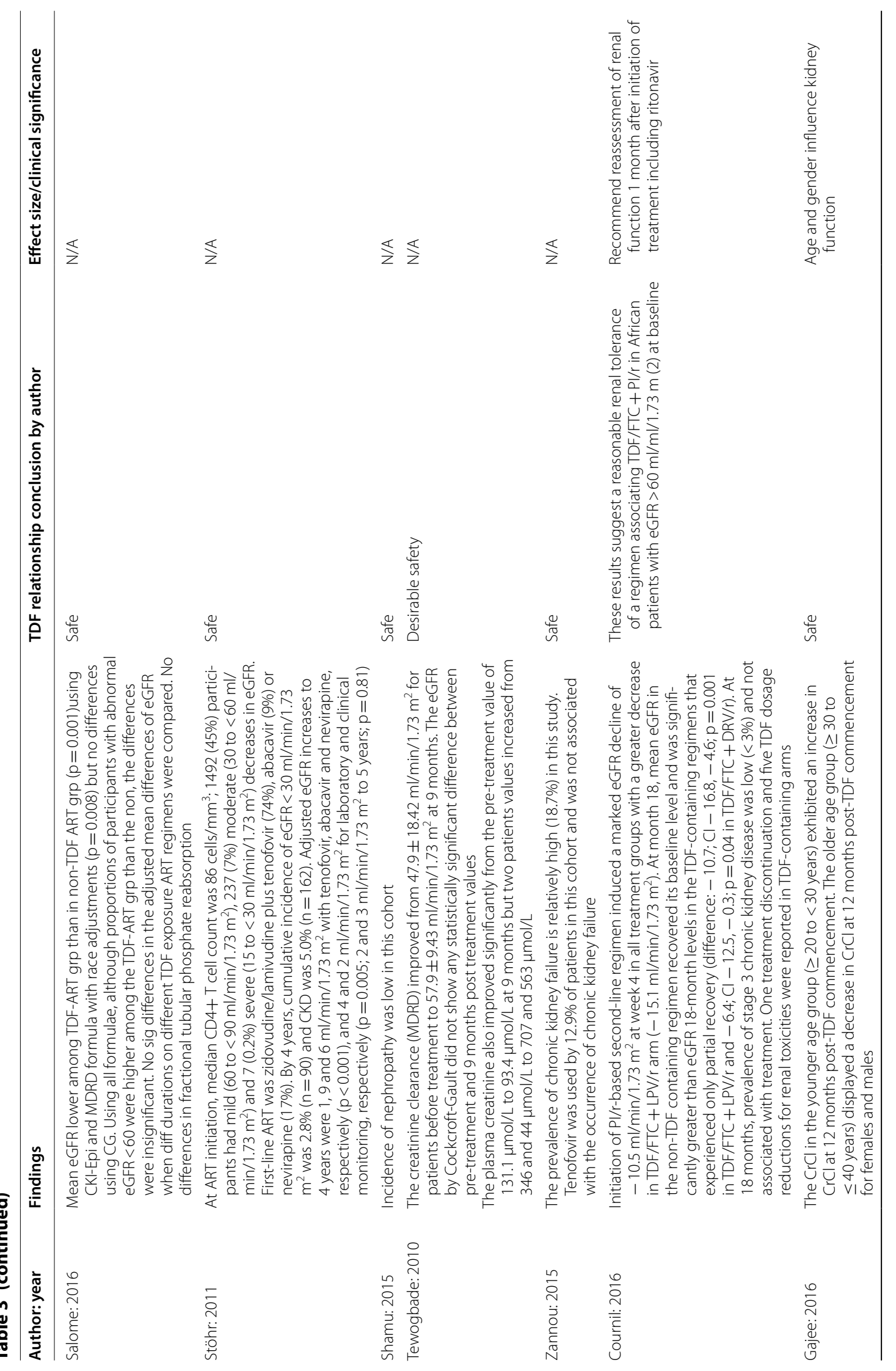




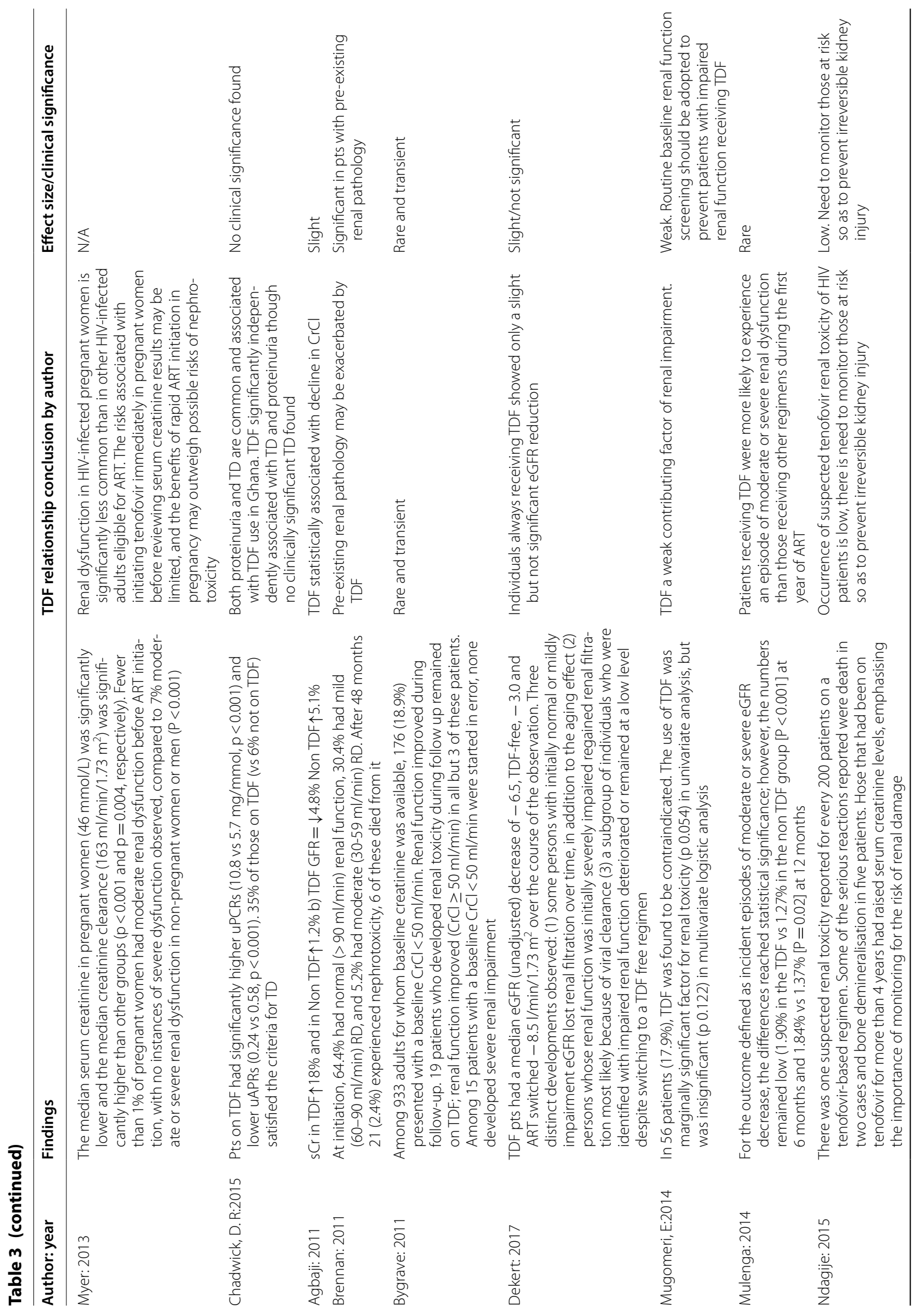




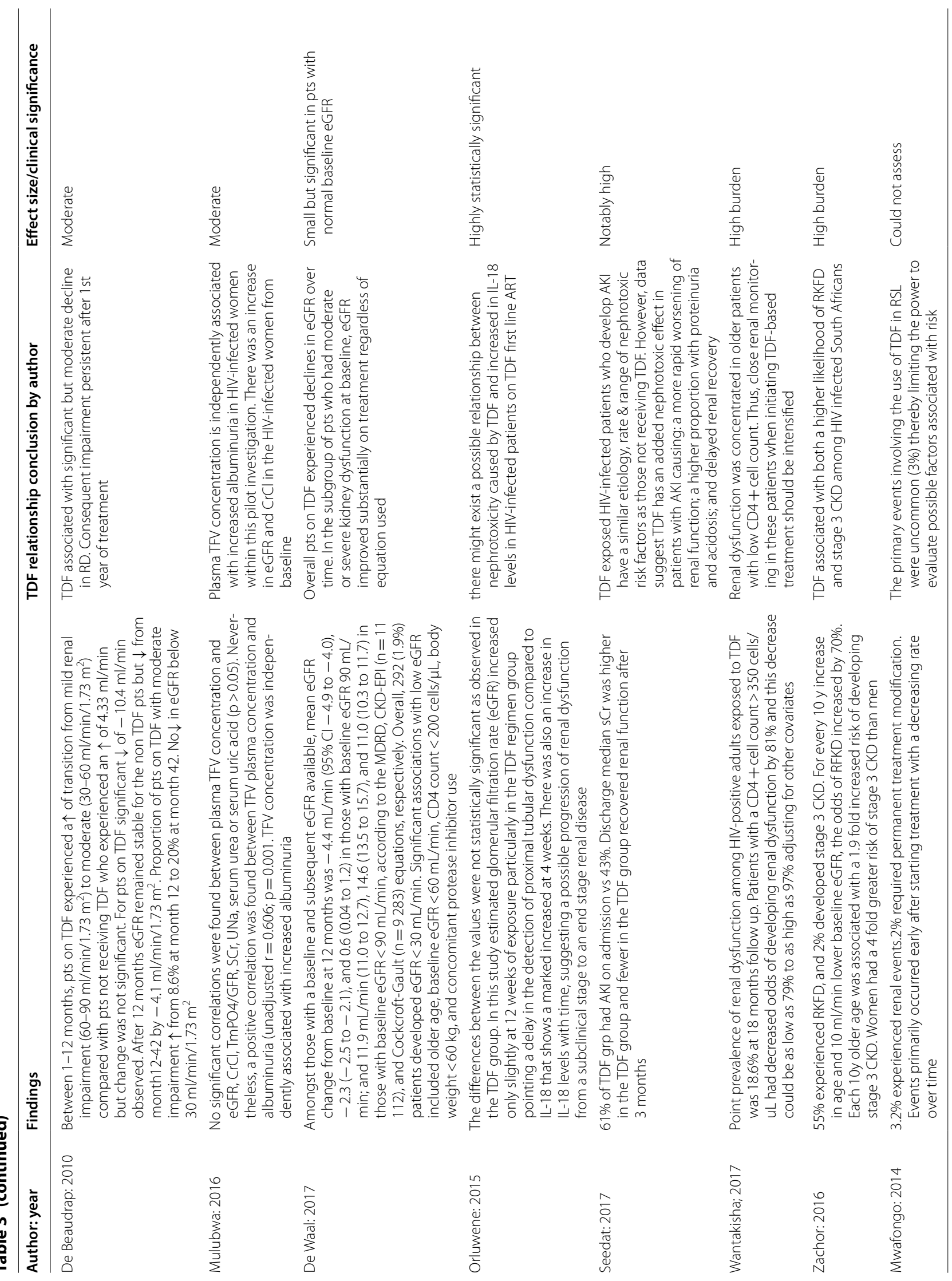




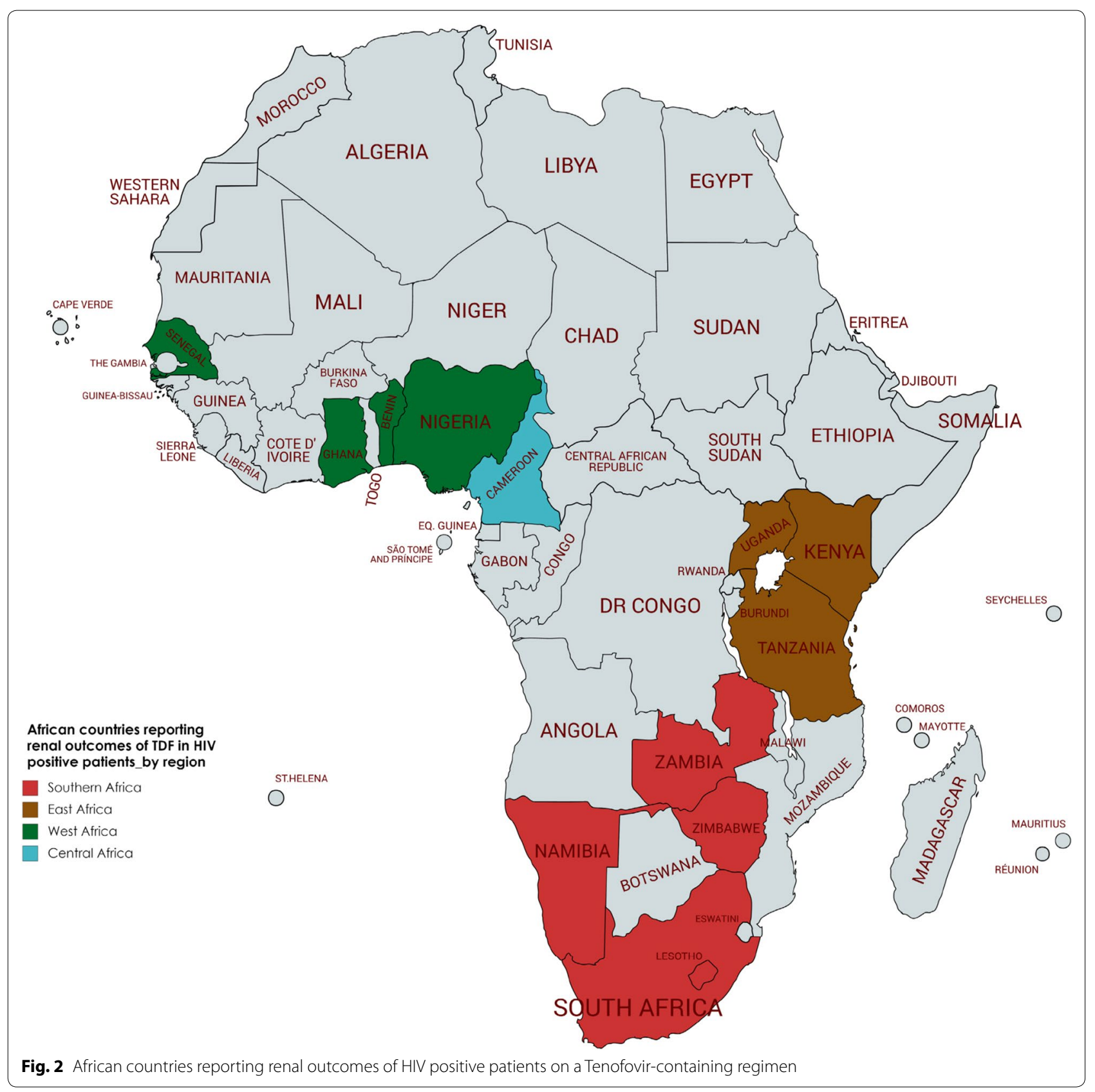

\section{Safety of TDF}

With ageing of the HIV populations in the era of ART, long-term complications of HIV such as renal disease become important. However, there are still limited drug safety data on tenofovir-associated renal dysfunction in adolescents and children. In this review, the studies reported were performed in adults mean age $\geq 33$ years; only one included patients below 16 years, being pregnant females aged 13 and older, the physiology of whom is not representative of other adolescents.
As such, these results may not generalizable to the younger populations who are in fact dosed the same as adults as long as they are $>35 \mathrm{~kg}$ or 10 years or older and will potentially take tenofovir for longer. It follows, therefore, that importance should be placed on monitoring the younger patients on TDF to potentially reduce co-morbidities with non-communicable diseases (NCDs) such as chronic kidney disease and also the potential burden of polypharmacy resulting later in life. This is especially important in the context 
of already strained African health systems. Given the recommendation and adoption of the test and treat approach and the fact that tenofovir is still in widespread use in African resource limited countries, it is imperative to further investigate the cumulative risk for TDF-associated nephrotoxicity during prolonged use in patients initiating its use early in their lives.

This review also notes that there is still a gap in knowledge of the impact of TDF in pregnant women against the background that TDF containing regimens are still the backbone of Prevention of Mother to Child Transmission (PMTCT) programmes in Africa. The three studies that focused on pregnant women all reported different outcomes: Myer reported that the risk of TDF associated toxicity is reduced in pregnant women, Mulubwa suggested that the risk is moderately higher in pregnant women while Mwafongo could not assess due to the small sample size [36, 43, 47].

Our review is the only such review done exclusively on Africans focusing on Tenofovir associated renal toxicity. A similar review had been conducted by Cooper et al. in 2012 but on high-income countries essentially excluding African countries. None of the studies found in this review focused on children or adolescents. In the review by Cooper, it was recommended that future trials focus on resource limited settings. It was noted in the present review that there has, indeed, been an increase in similar trials in resource limited settings since then [11]. Despite including patients of different ancestry, our results are in agreement with Cooper's review i.e. although relatively low and modest, there exists an association between TDF and renal decline. Several studies on different populations have investigated renal transporter single nucleotide polymorphisms (SNPs) related to possible TDF renal toxicity with conflicting results [57-62]. It may be important to do similar studies on patients of African ancestry in order to determine its contribution to the discussion and if found, the consequent effect size. The results observed in the various geographical areas within Africa, where the studies included in this review were performed, do not show any particular pattern in the outcomes, associated with any region.

\section{Future areas for developing research}

As mentioned in the 2016 WHO guidelines, further investigations are still required on the long term safety of tenofovir disoproxil fumarate as more data are needed on bone, growth and renal toxicity profiles in adolescents and children. More data are still needed to understand the possibility, impact and clinical implications of TDF toxicity in adolescents. Since Southern Africa seemed to report less desirable renal safety profiles of TDF in HIV positive patients, pharmacogenomic screening for specific genetic markers predisposing patients to renal disease may also be beneficial in identifying patients at higher risk of developing CKD in the different African populations.

Given that several studies have suggested a need for routine monitoring of patients on TDF, there is also still a gap in the systematic comparison and documentation of monitoring strategies that may be effective in these settings.

\section{Limitations of current study}

The study was limited by the available literature; it is possible that more studies may have been done in Africa but were not published by the time of this review. The heterogeneity in the definitions of renal outcomes and how they were reported had a negative impact on our pooled analysis of study results and the inability to perform an effective meta-analysis. Too few studies reported specific markers of proximal tubulopathy. While policies are clear on what needs to be checked for TDF induced nephropathy, there needs to be a better documentation on how best to report these in clinical practice to allow for more effective comparisons. There were only a few studies that reported concomitant ART regimens so this review could not assess the possibility of other ART as possible effect modifiers of TDF-associated nephrotoxicity. It is also important to note that the present review could not analyse for the effect of other diseases such as hypertension and diabetes on renal dysfunction as they were not systematically reported.

All studies were essentially conducted in adults; future research should focus on younger populations as the long term implications of HIV and ART become of greater cause for concern with an ageing HIV population on continued ART.

\section{Conclusions}

Our review identified studies in Africans reporting statistically significant renal function decline associated with TDF use but the clinical significance of this effect was not enough to contraindicate its continued use in ART regimens (Table 3). Consistent with studies in other populations, patients are at greater risk if they have pre-existing renal disease and are more advanced in age. However, more long term research is required (studying cohorts over at least a decade) that monitors clinically relevant markers specific for proximal tubulopathy. This is particularly important for younger, paediatric populations whose life expectancy has improved as they are potentially on ART for decades from childhood but are also at increased risk of developing NCDs such as diabetes, CVD and cancers which could also influence renal toxicity. 


\section{Additional file}

Additional file 1: Search strategy for Pubmed (as at 5 October 2017).

\begin{abstract}
Abbreviations
AKI: acute kidney injury; ART: antiretroviral treatment; CKD: chronic kidney disease; CKI-EPI: chronic kidney disease epidemiology collaboration; $\mathrm{CrCl}$ : creatinine clearance; D4T: stavudine; EFV: efavirenz; eGFR: estimated glomerular filtration rate; FTC: emtricitabine; HIV: human immunodeficiency virus; IL: interleukin; LPV: lopinavir; MDRD: modification of diet in renal disease; NVP: nevirapine; PMTCT: prevention of mother to child transmission; RCT: randomised control trial; RD: renal dysfunction; sCr: serum creatinine; SNP: single nucleotide polymorphism; TD: tubular dysfunction; TDF: tenofovir disproxil fumarate; TAF: tenofovir alafenamide.
\end{abstract}

\section{Acknowledgements}

Elizabeth Stellrecht assisted with the development of the search strategy. Admire Hlupeni $(\mathrm{AH})$ was the second reviewer for the searched articles.

\section{Authors' contributions}

TM was a main contributor in the design, implementation and writing of the manuscript GDM guided the study design and implementation. TM and $\mathrm{AH}$ reviewed the articles then CEN analyzed and interpreted the patient data regarding renal safety. All authors read and approved the final manuscript.

\section{Funding}

The project described was supported by Grant Number D43TW010313 from the Fogarty International Center. The content is solely the responsibility of the authors and does not necessarily represent the official views of the Fogarty International Center or the National Institutes of Health.

\section{Availability of data and materials}

The datasets during and/or analysed during the current study available from the corresponding author on reasonable request.

\section{Ethics approval and consent to participate \\ Not applicable.}

\section{Consent for publication}

Not applicable.

\section{Competing interests}

The authors declare that they have no competing interests.

\section{Author details}

${ }^{1}$ Department of Clinical Pharmacology, University of Zimbabwe College of Health Sciences, Harare, Zimbabwe. ${ }^{2}$ Department of Medicine, University of Zimbabwe College of Health Sciences, Harare, Zimbabwe. ${ }^{3}$ School of Pharmacy, University of Zimbabwe College of Health Sciences, Harare, Zimbabwe. ${ }^{4}$ Center for Integrated Global Biomedical Sciences; School of Pharmacy and Pharmaceutical Sciences, University at Buffalo, State University of New York, Buffalo, NY, USA.

Received: 18 March 2019 Accepted: 25 May 2019

Published online: 06 June 2019

\section{References}

1. Wishart DS, Knox C, Guo AC, Cheng D, Shrivastava S, Tzur D, et al. DrugBank: a knowledgebase for drugs, drug actions and drug targets. Nucleic Acids Res. 2008:36(Database issue):D901-6.

2. Knox C, Law V, Jewison T, Liu P, Ly S, Frolkis A, et al. DrugBank 3.0: a comprehensive resource for 'omics' research on drugs. Nucleic Acids Res. 2011;39(Database issue):D1035-41.

3. da Rocha IM, Gasparotto AS, Lazzaretti RK, Notti RK, Sprinz E, Mattevi VS. Polymorphisms associated with renal adverse effects of antiretroviral therapy in a Southern Brazilian HIV cohort. Pharmacogenet Genom. 2015:25(11):541-7.
4. Kohler JJ, Hosseini SH, Green E, Abuin A, Ludaway T, Russ R, et al. Tenofovir renal proximal tubular toxicity is regulated By OAT1 and MRP4 transporters. Lab Invest. 2011:91(6):852-8.

5. Pushpakom SP, Liptrott NJ, Rodríguez-Nóvoa S, Labarga P, Soriano $\checkmark$, Albalater M, et al. Genetic variants of ABCC10, a novel tenofovir transporter, are associated with kidney tubular dysfunction. J Infect Dis. 2011;204(1):145-53.

6. Rodriguez-Novoa S, Labarga P, Soriano V. Pharmacogenetics of tenofovir treatment. Pharmacogenomics. 2009;10(10):1675-85.

7. Rodriguez-Novoa S, Labarga P, Soriano V, Egan D, Albalater M, Morello J, et al. Predictors of kidney tubular dysfunction in HIV-infected patients treated with tenofovir: a pharmacogenetic study. Clin Infect Dis. 2009:48(11):e108-16.

8. Coca S, Perazella MA. Rapid communication: acute renal failure associated with tenofovir: evidence of drug-induced nephrotoxicity. Am J Med Sci. 2002;324(6):342

9. Fernandez-Fernandez B, Montoya-Ferrer A, Sanz AB, Sanchez-Niño MD, Izquierdo MC, Poveda J, et al. Tenofovir nephrotoxicity: 2011 update. AIDS Res Treat. 2011;2011:354908-11.

10. Nelson MR, Katlama C, Montaner JS, Cooper DA, Gazzard B, Clotet B, et al. The safety of tenofovir disoproxil fumarate for the treatment of HIV infection in adults: the first 4 years. AIDS (London, England). 2007;21:1273-81.

11. Cooper RD, Wiebe N, Smith N, Keiser P, Naicker S, Tonelli M. Systematic review and meta-analysis: renal safety of tenofovir disoproxil fumarate in HIV-infected patients. Clin Infect Dis. 2010;51(5):496-505.

12. Fabian J, Naicker S. HIV and kidney disease in sub-Saharan Africa. Nat Rev Nephrol. 2009;5(10):591-8.

13. Lucas GM, Lau B, Atta MG, Fine DM, Keruly J, Moore RD. Chronic kidney disease incidence, and progression to end-stage renal disease, in HIV-infected individuals: a tale of two races. J Infect Dis. 2008:197(11):1548-57.

14. Kalyesubula R, Perazella MA. Nephrotoxicity of HAART. AIDS Res Treat. 2011;2011:562790.

15. Brennan A, Evans D, Maskew M, Naicker S, Ive P, Sanne I, et al. Relationship between renal dysfunction, nephrotoxicity and death among HIV adults on tenofovir. AIDS (London, England). 2011;25(13):1603-9.

16. Langness JA, Hindman JT, Johnson SC, Kiser JJ. The frequency of adjusted renal dosing of tenofovir DF and its effects on patient outcomes. J Pharm Pract. 2013;26(4):397-400

17. Gupta SK. Tenofovir and changes in renal function. Clin Infect Dis. 2005;41(4):570-1.

18. Sax PE, Gallant JE, Klotman PE. Renal safety of tenofovir disoproxil fumarate. AIDS Reader. 2007;17(2):90-2.

19. Wang H, Lu X, Yang $X, X u N$. The efficacy and safety of tenofovir alafenamide versus tenofovir disoproxil fumarate in antiretroviral regimens for HIV-1 therapy: meta-analysis. Medicine. 2016;95(41):e5146.

20. Moher D, Liberati A, Tetzlaff J, Altman DG, The PG. Preferred reporting items for systematic reviews and meta-analyses: the PRISMA statement. PLoS Med. 2009;6(7):e1000097.

21. Masese LA, Okalebo FA, Mwangangi LEM, Bosire KO, Mwangi M. Comparison of the renal safety of tenofovir and stavudine in patients on antiretroviral therapy at a kenyan referral hospital. Pharmacoepidemiol Drug Saf. 2012;21:95.

22. Agbaji OO, Agaba PA, Idoko JA, Taiwo B, Murphy R, Kanki P, et al. Temporal changes in renal glomerular function associated with the use of tenofovir disoproxil fumarate in HIV-infected Nigerians. West Afr J Med. 2011;30(3):164-8.

23. Beaudrap PD, Diallo MB, Landman R, Gueye NF, Ndiaye I, Diouf A, et al. Changes in the renal function after tenofovir-containing antiretroviral therapy initiation in a Senegalese cohort (ANRS 1215). AIDS Res Hum Retroviruses. 2010;26(11):1221-7.

24. Bygrave H, Kranzer K, Hilderbrand K, Jouquet G, Goemaere E, Vlahakis $\mathrm{N}$, et al. Renal safety of a tenofovir-containing first line regimen: experience from an antiretroviral cohort in rural lesotho. PLOS ONE. 2011;6(3):e17609.

25. De Waal R, Cohen K, Fox MP, Stinson K, Maartens G, Boulle A, et al. Changes in estimated glomerular filtration rate over time in South African HIV-1-infected patients receiving tenofovir: a retrospective cohort study. J Int AIDS Soc. 2017;20(1):1-8.

26. Deckert A, Neuhann F, Klose C, Bruckner T, Beiersmann C, Haloka J, et al. Assessment of renal function in routine care of people living with 
HIV on ART in a resource-limited setting in urban Zambia. PLoS ONE. 2017;12(9):e0184766.

27. Hema A, Cournil A, Ciaffi L, Eymard-Duvernay s, Diouf a, Manga n, et al. Impact of TDF + PI/R on renal function in Sub-Saharan Africa: 2LADY/ ANRS 12169 trial. Topics Antiviral Med. 2015;23(358):635-8.

28. Kalemeera F, Mbango C, Mubita M, Naikaku E, Gaida R, Godman B. Effect of changing from first- to second-line antiretroviral therapy on renal function: a retrospective study based on data from a single health facility in Namibia. Exp Rev Anti-Infect Ther. 2016;14(8):777-83.

29. Kamkuemah M, Kaplan R, Bekker LG, Little F, Myer L. Renal impairment in HIV-infected patients initiating tenofovir-containing antiretroviral therapy regimens in a Primary Healthcare Setting in South Africa. Trop Med Int Health. 2015;20(4):518-26.

30. Mayanja BN, Kasamba I, Levin J, Namakoola I, Kazooba P, Were J, et al. COHORT PROFILE: the complications of long-term antiretroviral therapy study in Uganda (CoLTART), a prospective clinical cohort. AIDS Res Ther. 2017;14:26.

31. Mpondo BCT, Kalluvya SE, Peck RN, Kabangila R, Kidenya BR, Ephraim $L$, et al. Impact of antiretroviral therapy on renal function among HIV-infected Tanzanian adults: a retrospective cohort study. PLOS ONE. 2014;9(2):e89573.

32. Mugomeri E, Olivier D, Van Den Heever-Kriek E. The effect of tenofovir in renal function in HIV-positive adult patients in the Roma health service area, Lesotho, southern Africa. J Int AIDS Soc. 2014;17(4):124-5.

33. Mulenga L, Musonda P, Mwango A, Vinikoor MJ, Davies MA, Mweemba $A$, et al. Effect of baseline renal function on tenofovircontaining antiretroviral therapy outcomes in Zambia. Clin Infect Dis. 2014;58(10):1473-80.

34. Seedat F, Martinson N, Motlhaoleng K, Abraham P, Mancama D, Naicker S, et al. Acute kidney injury, risk factors, and prognosis in hospitalized HIVinfected adults in South Africa, compared by tenofovir exposure. AIDS Res Hum Retroviruses. 2017;33(1):33-40.

35. Zachor H, Machekano R, Estrella MM, Veldkamp PJ, Zeier MD, Uthman $\mathrm{OA}$, et al. Incidence of stage 3 chronic kidney disease and progression on tenofovir-based regimens. AIDS (London, England). 2016;30(8):1221-8.

36. Myer L, Kamkuemah M, Kaplan R, Bekker LG. Low prevalence of renal dysfunction in HIV-infected pregnant women: implications for guidelines for the prevention of mother-to-child transmission of HIV. Trop Med Int Health. 2013;18(11):1400-5.

37. Shamu T, Wellington M, Pascoe M, Gwanzura L, Ndhlovu C. Incidence of nephropathy in HIV infected patients receiving highly active antiretroviral therapy at Newlands Clinic: a retrospective study. World J AIDS. 2015;5(02):113.

38. Gajee AA. The renal safety profile of tenofovir as used in combination antiretroviral therapy: North-West University (South Africa), Potchefstroom Campus; 2016.

39. Tewogbade AA. Effects of highly active antiretroviral therapy haart on the renal function of HIV/AIDS patients at the university of Ilorin Teaching Hospital, Ilorin. Faculty of Pathology: Nigeria; 2010

40. Banda J, Mweemba A, Siziya S, Mweene M, Andrews B, Lakhi S. Prevalence and factors associated with renal dysfunction in HIV positive and negative adults at the University Teaching Hospital, Lusaka. Med I Zambia. 2010:37(3):136-42.

41. Chadwick DR, Sarfo FS, Kirk ES, Owusu D, Bedu-Addo G, Parris V, et al. Tenofovir is associated with increased tubular proteinuria and asymptomatic renal tubular dysfunction in Ghana. BMC Nephrol. 2015;16:195.

42. Fritzsche C, Rudolph J, Huenten-Kirsch B, Hemmer CJ, Tekoh R, Kuwoh PB, et al. Effect of tenofovor diproxil fumarate on renal function and urinalysis abnormalities in HIV-infected Cameroonian adults. Am J Trop Med Hyg. 2017:97(5):1445-50.

43. Mulubwa M, Rheeders M, Fourie C, Viljoen M. Associations between plasma tenofovir concentration and renal function markers in HIVinfected women. S Afr J HIV Med. 2016;17(1):a458.

44. Salome T, Kasamba I, Mayanja BN, Kazooba P, Were J, Kaleebu P, et al. The effect of Tenofovir on renal function among Ugandan adults on longterm antiretroviral therapy: a cross-sectional enrolment analysis. AIDS Res Ther. 2016;13(1):28.

45. Wantakisha E, Chongwe G, Munkombwe D, Michelo C. Renal dysfunction among HIV-infected patients on tenofovir-based antiretroviral therapy at Ronald Ross Hospital in Zambia. J AIDS Clin Res. 2017;8(1):651.
46. Zannou D, Vigan J, Azon-Kouanou A, Agboton B, Houngbe C. Prevalence of chronic kidney failure and associated factors in patients treated by antiretroviral in the national teaching hospital of Cotonou. J Nephrol Ther 2015;5(214):2161

47. Mwafongo A, Nkanaunena K, Zheng Y, Hogg E, Samaneka W, Mulenga L, et al. Renal events among women treated with tenofovir/emtricitabine in combination with either lopinavir/ritonavir or nevirapine. AIDS (London, England). 2014;28(8):1135-42.

48. Cournil A, Hema A, Eymard-Duvernay S, Ciaffi L, Badiou S, Kabore FN, et al. Evolution of renal function in African patients initiating secondline antiretroviral treatment: findings from the ANRS 12169 2LADY trial. Antiviral Ther. 2017;22(3):195-203.

49. Reid A, Stöhr W, Walker AS, Williams IG, Kityo C, Hughes P, et al. Severe renal dysfunction and risk factors associated with renal impairment in HIV-infected adults in Africa initiating antiretroviral therapy. Clin Infect Dis. 2008;46(8):1271-81.

50. Stöhr W, Reid A, Walker AS, Ssali F, Munderi P, Mambule I, et al. Glomerular dysfunction and associated risk factors over 4-5 years following antiretroviral therapy initiation in Africa. Antiviral Ther. 2011;16(7):1011-20.

51. Orluwene CG, Deebii N, Odum EP. Urinary interleukin (II)-18 as an early predictive biomarker of subclinical proximal tubular dysfunction in HIVinfected patients exposed to tenofovir. J AIDS Clin Res. 2015;6(9):497.

52. Ndagije H, Nambasa V, Namagala E, Nassali H, Kajungu D, Sematiko G, et al. Targeted spontaneous reporting of suspected renal toxicity in patients undergoing highly active anti-retroviral therapy in two public health facilities in Uganda. Drug Saf. 2015;38(4):395-408.

53. Chadwick, Sarfo FS, Kirk ESM, Owusu D, Bedu-Addo G, Parris V, et al. Tenofovir is associated with increased tubular proteinuria and asymptomatic renal tubular dysfunction in Ghana. BMC Nephrol. 2015;16(1):195.

54. Hill A, Hughes SL, Gotham D, Pozniak AL. Tenofovir alafenamide versus tenofovir disoproxil fumarate: is there a true difference in efficacy and safety? J Virus Erad. 2018;4(2):72-9.

55. Andrade-Fuentes K, Mata-Marin JA, Lopez-De Leon JI, Manjarrez-Tellez B, Ramirez JL, Gaytan-Martinez J. Proximal renal tubular dysfunction related to antiretroviral therapy among HIV-infected patients in an HIV clinic in Mexico. AIDS Patient Care STDs. 2015:29(4):181-5.

56. Bonjoch A, Echeverria P, Perez-Alvarez N, Puig J, Estany C, Clotet B, et al. Prospective study to assess progression of renal markers after interruption of tenofovir due to nephrotoxicity. Biomed Res Int. 2016;2016:4380845.

57. Arruda MB, Campagnari F, de Almeida TB, Couto-Fernandez JC, Tanuri A, Cardoso CC. Single nucleotide polymorphisms in cellular drug transporters are associated with intolerance to antiretroviral therapy in Brazilian HIV-1 positive individuals. PLoS ONE. 2016;11(9):e0163170.

58. Cheong HS, Kim HD, Na HS, Kim JO, Kim LH, Kim SH, et al. Screening of genetic variations of SLC15A2, SLC22A1, SLC22A2 and SLC22A6 genes. J Hum Genet. 2011;56(9):666-70.

59. Limou S, Nelson GW, Kopp JB, Winkler CA. APOL1 kidney risk alleles: population genetics and disease associations. Adv Chronic Kidney Dis. 2014;21(5):426-33.

60. Manosuthi W, Sukasem C, Thongyen S, Nilkamhang S, Sungkanuparph S. ABCC2*1C and plasma tenofovir concentration are correlated to decreased glomerular filtration rate in patients receiving a tenofovir-containing antiretroviral regimen. J Antimicrob Chemother. 2014;69(8):2195-201.

61. Nishijima T, Hayashida T, Kurosawa T, Tanaka N, Oka S, Gatanaga H. Drug transporter genetic variants are not associated with TDF-related renal dysfunction in patients with HIV-1 infection: a pharmacogenetic study. PLOS ONE. 2015;10(11):e0141931.

62. Rungtivasuwan K, Avihingsanon A, Thammajaruk N, Mitruk S, Burger $D M$, Ruxrungtham $\mathrm{K}$, et al. Influence of $<\mathrm{em}>\mathrm{ABCC} 2</ \mathrm{em}>$ and $<$ em $>A B C C 4</$ em $>$ polymorphisms on tenofovir plasma concentrations in Thai HIV-infected patients. Antimicrob Agents Chemother. 2015;59(6):3240-5.

\section{Publisher's Note}

Springer Nature remains neutral with regard to jurisdictional claims in published maps and institutional affiliations. 